\title{
Avaliação do saber ambiental de professores do ensino público do município de São Bento, Paraíba
}

Evaluation of environmental knowledge of public school teachers in São Bento, Paraiba

\author{
E. Silva ${ }^{1 *}$; F. G. Silva ${ }^{1}$; R. F. L. Silva ${ }^{1}$; R. H. Silva ${ }^{1}$;H. M. Oliveira ${ }^{2}$ \\ ${ }^{1}$ Unidade Acadêmica de Ciências Biológicas, Universidade Federal de Campina Grande, CEP58708-110,Patos-PB, \\ Brasil \\ ${ }^{2}$ Unidade Acadêmica de Ciências Agárias, Universidade Federal de Campina Grande, CEP 58840-000, Pombal -
} $P B$, Brasil

*edevaldo@cstr.ufcg.edu.br

(Recebido em 01 de maio de 2015; aceito em 18 de agosto de 2015)

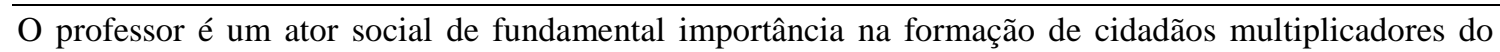
saber ambiental. Esse trabalho teve o objetivo de analisar o conhecimento dos professores do município de São Bento, Paraíba, quanto à Educação Ambiental. Foram entrevistados 21 professores de três escolas de ensino fundamental público. Os dados foram coletados por meio de um questionário contendo 12 perguntas sobre Educação Ambiental, desenvolvimento sustentável e dez temas ambientais. Além de outras variáveis (gênero, idade, titulação, tempo de ensino). O conhecimento dos professores variou entre pouco ou saber em parte sobre os temas ambientais. Houve diferença no nível de conhecimento entre gêneros, sendo maior no gênero masculino. Observou-se correlação positiva entre o tempo de ensino e o maior conhecimento do professor. A maioria deles apresentaram dificuldades em conceituar o que é Educação Ambiental e desenvolvimento sustentável. Esse cenário revela a grande necessidade de capacitação docente em Educação Ambiental.

Palavras-chave: Meio ambiente, Docente, Capacitação

The teacher is a social actor of fundamental importance in the formation of multipliers citizens of environmental knowledge. This work aimed to analyze the knowledge of teachers in São Bento, Paraiba, on the Environmental Education. We interviewed 21 teachers from three schools of public elementary school. Data were collected through a questionnaire containing 12 questions about Environmental Education, sustainable development and 10 environmental issues. In addition, other variables (gender, age, degree, teaching time). Knowledge of teachers ranged from little to know in part on environmental issues. There were differences in the level of knowledge between genders, being greater in males. There was a positive correlation between teaching time and the greater knowledge of the teacher. Most of them had difficulties in conceptualizing what is environmental education and sustainable development. This scenario shows the great need for teacher training in Environmental Education.

Keywords:Environment, Teacher, Training

\section{INTRODUÇÃO}

As questões ambientais vêm sendo foco de intensas e recorrentes discussões, assumindo uma função transformadora, onde a participação dos indivíduos é essencial para a promoção do desenvolvimento sustentável [1].

A problemática ambiental expande-se de maneira gradual, imperceptível e a curto prazo, a medida que vivenciamos uma expansão social e urbana. De modo que a preservação ambiental tornou-se um desafio para a melhoria da qualidade de vida e a sociedade começou a cobrar das escolas uma educação voltada para conscientização ambiental que possibilitasse a construção do saber a partir dos instrumentos e recursos naturais disponíveis [2].

No Brasil, a Educação Ambiental ganhou notoriedade com a promulgação da lei que instituiu a Política Nacional de Educação Ambiental (PNEA, Lei 9.795 de 27 de abril de 1999) tornando- 
se indispensável no cenário educacional nacional em todos os níveis, formal e não formais. Apesar disso, ela ainda estabelece uma relação com a educação repleta de contradições e distanciamentos, com poucos e rasos diálogos [3].

De acordo com Luca et al. (2012) [4], o diálogo é uma ferramenta necessária e de grande utilidade para a Educação Ambiental e também para os educadores ambientais, pois, este artifício permite que uma linha de coexistência se fortaleça entre as diferentes realidades e que baseados numa perspectiva pedagógica dialógica, esses profissionais busquem os melhores procedimentos para tornar os espaços de aprendizagem em fontes de conhecimento e alimento intelectual.

O tratado e os diferentes enclaves trabalhados na Educação Ambiental podem proporcionar o encontro de saberes e ações, que ao ocorrer dessa forma, vislumbram-se práticas solidárias por meio da interação social e a aplicação edificante do conhecimento [5].

A Educação Ambiental não representa somente uma resposta aos desafios atuais, mais também uma educação crítica e transformadora, capaz de incentivar o desenvolvimento de valores e atitudes que conduzam os sujeitos da educação a se inserir em processos democráticos de transformação das modalidades de uso dos recursos naturais e sociais [6].

Para uma maior contribuição na formação da cidadania, a Educação Ambiental carece mais de atitudes e formação de valores, do que apenas informações e conceitos, visto que a atuação direta de cidadãos conscientes torna-se uma das únicas alternativas viáveis para reverter o quadro da problemática ambiental [7].

Embora o termo Educação Ambiental nos remeta a uma educação para o meio ambiente, as formas como essa educação é pensada e praticada podem implicar diferentes práticas e maneiras de como ela tem sido trabalhada, revelando distintas percepções sobre o meio ambiente construídas ao longo dos anos $[8,9]$.

Bortolozzi e Perez Filho (2000) [10], afirmam que no Brasil a qualidade do ensino na escola pública é um fator que pode estar diretamente ligado a qualidade de vida e não deve ser visto como sendo distinto dos demais problemas sociais enfrentados. Ele ainda reitera que condições confusas de cunho ambiental devem ser reformuladas e que aspectos integradores entre natureza e sociedade devem ser estabelecidos, sendo a escola capaz de tamanha imposição.

O professor representa um mediador fundamental no processo de implementação da Educação Ambiental no currículo escolar e, no quadro de uma crise ambiental na qual se inserem os sujeitos, o currículo deve explorar a sua dimensão cultural e imaginária, oferecendo oportunidades, a professor e aluno, para a construção e reconstrução de representações mais apropriadas a um novo significado e papel a ser desempenhado por eles no domínio ambiental [11].

Projetos desenvolvidos nessa área são úteis no sentido de esclarecer ao estudante sobre os benefícios da conscientização e da conservação do meio ambiente, podendo ser trabalhado nas escolas da educação básica de modo transversal aos demais conteúdos curriculares [12].

Entretanto, Cuba (2010) [13] defende a ideia de que ela deve ser vista e tratada cientificamente no âmbito escolar, atuando separadamente das outras disciplinas, já que muitas vezes é esquecida, devido ao fato dos alunos ficarem presos aos conteúdos curriculares. $\mathrm{O}$ mesmo autor reconhece a necessidade de eliminação das barreiras entre as disciplinas e entre os profissionais da educação. E, o desafio consiste na capacidade de mobilizar os saberes fragmentados para formar novos territórios do conhecimento, abertos e dinâmicos, que respondam às necessidades de nosso tempo e às nossas interrogações cognitivas [5].

A Educação Ambiental deve reorientar e articular diversas disciplinas e experiências educativas que facilitem a visão integrada do meio ambiente, proporcionando vinculação mais estreita entre os processos educativos e a realidade. No entanto, os educadores, em sua grande maioria, não atribuem ao tema à devida importância, ou sentem-se despreparados para lidar com essas questões [14].

De acordo com Jacobi (2005) [15] os educadores têm um papel estratégico e decisivo na inserção da Educação Ambiental no cotidiano escolar e na qualificação dos alunos para um posicionamento crítico frente à crise socioambiental, onde estes devem estar mais preparados para reelaborar as informações que recebem, permitindo assim transmitir e decodificar para os 
alunos a expressão dos significados em torno do meio ambiente e da ecologia nas suas múltiplas determinações e inter-relações.

Esse autor ainda reitera que o papel dos professores é essencial para impulsionar as transformações de uma educação que assume um compromisso com o desenvolvimento sustentável e também com as futuras gerações, e a inserção da educação ambiental numa perspectiva crítica ocorre na medida em que o professor assume uma postura reflexiva.

Os aspectos pedagógicos da Educação Ambiental não devem ser apenas discutidos e vislumbrados pelos educadores ambientais, e sim tornarem-se uma prática constante e possível, utilizando-se do que a realidade pode oferecer. Esse contexto vem se consolidando com motivações no território nacional [16].

Bizerril e Faria (2001) [17] afirmam que a falta de segurança dos professores em assuntos relacionados à Educação Ambiental pode estar diretamente ligada ao desinteresse por tais temas, e que quando se faz necessário diferentes métodos para conteúdo de ensino não formais, esses profissionais ficam apreensivos pelas expectativas e acabam não procurando algum tipo de preparo para lecionar tais temas ou assuntos.

Segundo Guimarães e Inforsato (2012) [18] a crise ambiental, atrelada à crise do conhecimento científico, exige um novo papel das universidades e dos cursos de formação de professores, sendo, portanto, incoerente exigir que um professor trabalhe ideias, conceitos, valores, habilidades e atitudes que colaborem com a formação de uma sociedade ambientalmente responsável, se ele não foi assim formado e nem recebeu uma formação continuada para isso.

Diante desse cenário, esse trabalho teve como objetivo analisar o nível de conhecimento dos professores da rede pública do município de São Bento, estado da Paraíba, sobre os temas atuais relacionados à Educação Ambiental.

\section{MATERIAL E MÉTODOS}

A pesquisa foi realizada no município de São Bento, Paraíba, em três escolas de ensino fundamental: Escola Municipal de Educação Infantil e Ensino Fundamental Dr. Jarques Lúcio da Silva, Escola Municipal de Educação Infantil e Ensino Fundamental Maria Dulce dos Santos e Escola Estadual de Ensino Fundamental e Médio João Silveira Guimarães.

O tamanho amostral foi estabelecido segundo Rocha (1997) [19], definindo a amostra a partir do número total de professores que ensinam no ensino fundamental dessas escolas e, considerando um erro padrão de 5\%. Dessa forma, foi determinada uma amostra de 21 professores, sendo realizada de forma aleatória simples.

Os dados foram coletados por meio da aplicação de um questionário contendo perguntas discursivas e de múltipla escolha. As perguntas de múltipla escolha foram 10, constituídas de temas ambientais, a saber: desertificação, escassez de recursos hídricos, mudanças climáticas, poluição atmosférica, poluição das águas, leis ambientais do Brasil, biodiversidade, desenvolvimento sustentável, coleta seletiva e consumo consciente.

As perguntas de múltipla escolha foram elaboradas segundo o modelo da escala de Likert, com cinco níveis de resposta: nível 1 - insuficiente; nível 2 - não sei em grande parte; nível 3 sei pouco; nível 4 - sei em grande parte; nível 5 - sei muito sobre o tema.

Duas questões discursivas foram abordadas: "O que é Educação Ambiental?" e "o que é desenvolvimento sustentável?". Foi ainda avaliado o perfil do professor (tempo de ensino público, graduação, pós-graduação) e variáveis de classificação (sexo, idade).

A análise das respostas discursivas foi avaliada de forma qualitativa e quantitativa. A partir do foco central das respostas sobre o conceito de "Educação Ambiental", sendo agrupadas em cinco tendências: conscientizar para preservar o ambiente; conscientizar para uso consciente dos recursos naturais; educar para promover a harmonia homem-natureza; educar para o uso consciente dos recursos naturais e não respondido ou respostas equivocadas. Enquanto que as respostas para o conceito de desenvolvimento sustentável foram avaliadas quanto a sua tendência de envolver na conceituação dos professores os seus aspectos sociais, ambientais e econômicos. 
A análise das respostas construídas no modelo da escala de Likert se deu por meio da estatística descritiva, utilizando o software Microsoft Excel 365, onde gerou-se, também, o escore médio do nível de conhecimento de todos os professores para cada tema ambiental baseados nos cinco níveis de respostas.

Para a análise de possíveis diferenças no nível de conhecimento entre os gêneros realizou-se a teste de Mann-Whitney e a análise de correlação entre o nível de conhecimento, a idade e o tempo de ensino foram analisados por meio de correlação simples (Spearman), através do software SPSS 20.0, considerando os níveis de probabilidade $\mathrm{p}<0,01$ e $\mathrm{p}<0,05$.

Esta pesquisa está de acordo com a Resolução $n^{\circ}$ 466/2012 do conselho nacional de saúde que rege sobre a ética da pesquisa envolvendo seres humanos direta ou indiretamente assegurando a garantia de que a privacidade do sujeito da pesquisa será preservada com todos os direitos sobre os princípios éticos como beneficência, respeito e justiça [20], estando registrada no Comitê de Ética e Pesquisa da Universidade Federal de Campina Grande (CAEE 37093714.0.0000.5182/ Parecer: 853.788).

\section{RESULTADOS E DISCUSSÃO}

Dentre os professores entrevistados, 52,4\% foram do gênero feminino e $47,6 \%$ do gênero masculino. A maior frequência de professores (Tabela 1) possuía faixa etária entre 26 a 39 anos e, $42,8 \%$ deles entre 13 e 18 anos de ensino na rede pública (Tabela 1).

Grande parte dos professores $(76,2 \%, \mathrm{n}=16)$ possuíam graduação na área de ciências sociais e humanas (pedagogia, letras, história e geografia) e 23,8\% $(n=5)$ apresentavam formação na área de ciências naturais e exatas (biologia e matemática). A maioria dos professores $(61,9 \%, \mathrm{n}$ = 13) tinham capacitação a nível de pós-graduação Latu sensu nos seguintes cursos: Psicopedagogia $(n=04)$, Supervisão escolar $(n=02)$, Língua/Linguística $(n=02)$, Geopolítica $(\mathrm{n}=02)$, Educação matemática $(\mathrm{n}=01)$, Fundamentos da educação $(\mathrm{n}=01)$ e Educação ambiental $(\mathrm{n}=01)$.

Tabela 01 - Frequência absoluta (fa) e percentual (fr) da idade (anos) e tempo de ensino público (anos) dos professores entrevistados

\begin{tabular}{ccc||ccc}
\multicolumn{6}{c}{$(N=21)$} \\
\hline Idade & Fr & Fa & $\begin{array}{c}\text { Tempo de } \\
\text { ensino }\end{array}$ & fr & Fa \\
\hline $19-25$ & 14,3 & 3 & $1-6$ & 23,8 & 5 \\
$26-32$ & 23,8 & 5 & $7-12$ & 9,5 & 2 \\
$33-39$ & 28,6 & 6 & $13-18$ & 42,8 & 9 \\
$40-46$ & 9,5 & 2 & $19-24$ & 4,8 & 1 \\
$47-53$ & 19,0 & 4 & $25-30$ & 14,3 & 3 \\
$54-60$ & 4,8 & 1 & $54-60$ & 4,8 & 1 \\
\hline
\end{tabular}

Fonte: Autores.

Segundo Mazzarino e Rosa (2013) [21], os professores que não atuam na área de ciências não têm conhecimento específico sobre a área ambiental, já que no seu currículo de formação não houve alusão a essa temática, realidade que persiste nos currículos universitários.

Esse fato torna-se uma limitação para esses educadores estabelecerem uma visão crítica e reflexiva sobre o meio ambiente, fato que tem comprometido a abordagem do conhecimento ambiental no âmbito escolar, uma vez, que o saber insuficiente e, muitas vezes, a insegurança em transmiti-los tem sido um fator determinante para que se evite trabalhar com temas ambientais em sala de aula.

De acordo com Matos (2009) [22] para que se possa entender a formação de educadores ambientais precisa-se passar por uma compreensão profunda do complexo contexto em que se insere a formação desses educadores, sendo que um educador ambiental não se capacita apenas 
por meio de uma formação ambiental, é necessário que essa formação contemple a articulação entre os conhecimentos pedagógicos, científicos e ambientais.

No que se refere aos seus conhecimentos sobre os temas ambientais mais recorrentes atualmente, foi observado que a maior parte dos professores afirmou ter pouco conhecimento sobre esses temas, especialmente no que diz respeito às leis ambientais brasileiras e a desertificação, onde $85,7 \%$ e $61,9 \%$, respectivamente, afirmaram possuir um conhecimento que variou entre insuficiente a pouco.

Por outro lado, os temas ambientais que a maioria dos professores afirmaram saber e em grande parte foram: poluição atmosférica $(61,9 \%)$, coleta seletiva $(61,9 \%)$, escassez de recursos hídricos $(57,1 \%)$ e consumo consciente $(57,1 \%)$.

Considerando a média de pontos (escore médio) de todos os professores para cada tema, observou-se que, em geral, o nível de conhecimento variou entre 3,0 e 4,0 de pontos médios, ou seja, entre o saber pouco (escore médio próximo a 3,0) e saber em grande parte (escore médio próximo a 4,0) dos temas avaliados. Exceto para leis ambientais do Brasil, onde eles revelaram um nível de conhecimento mais baixo (média 2,6 - não sabem em grande parte sobre o tema).

Apesar da média geral para alguns temas serem próximas ao nível de conhecimento onde os professores declararam saber muito sobre o tema (próximo ao escore igual a 4,0), verifica-se na Tabela 2 que, para todos os temas, cerca de 1/3 dos professores afirmaram saber pouco (alternativa "sei pouco"). Essa realidade, demonstra que uma parcela significativa dos professores entrevistados possui um conhecimento limitado sobre os temas ambientais mais recorrentes atualmente, fato preocupante, pois os professores são um dos principais atores no processo de formação do aluno para um pensamento crítico e sensibilizado em relação as questões ambientais. Dessa maneira, a sua capacidade em desenvolver esses temas é fundamental.

Tabela 02 - Frequência percentual (fr) e escore médio do conhecimento dos professores para dez temas ambientais mais recorrentes na atualidade $(N=21)$.

\begin{tabular}{|c|c|c|c|c|c|c|}
\hline Temas Ambientais & 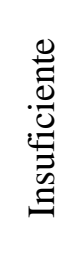 & 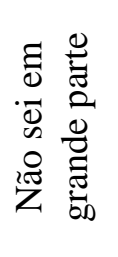 & 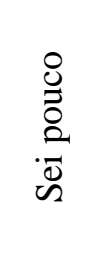 & 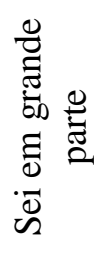 & 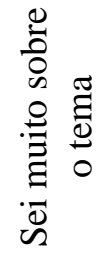 & 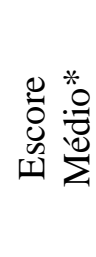 \\
\hline Desertificação & 4,8 & 28,6 & 28,6 & 28,6 & 9,5 & 3,1 \\
\hline Escassez de recursos hídricos & 4,8 & 9,5 & 28,6 & 38,1 & 19,0 & 3,5 \\
\hline Mudanças climáticas & 0,0 & 9,5 & 42,9 & 23,8 & 23,8 & 3,6 \\
\hline Poluição atmosférica & 0,0 & 4,8 & 33,3 & 33,3 & 28,6 & 3,8 \\
\hline Poluição das águas & 0,0 & 0,0 & 47,6 & 28,6 & 23,8 & 3,7 \\
\hline Leis ambientais do Brasil & 9,5 & 38,1 & 38,1 & 4,8 & 9,5 & 2,6 \\
\hline Biodiversidade & 4,8 & 23,8 & 28,6 & 38,1 & 4,8 & 3,2 \\
\hline Desenvolvimento sustentável & 4,8 & 9,5 & 42,9 & 33,3 & 9,5 & 3,3 \\
\hline Coleta seletiva & 4,8 & 9,5 & 23,8 & 33,3 & 28,6 & 3,7 \\
\hline Consumo consciente & 0,0 & 4,8 & 38,1 & 28,6 & 28,6 & 3,8 \\
\hline
\end{tabular}

Fonte: Autores.

* Valor médio da pontuação de todos os professores, considerando uma escala de 1 (insuficiente) a 5 (conhecimento).

A análise estatística reportou que o nível de conhecimento variou significativamente $(p<0,05)$ entre os gêneros masculino e feminino.

Além disso, houve correlação positiva e muito significativa $(\mathrm{p}<0,01)$ entre o nível de conhecimento e o tempo de ensino dos professores, ou seja, os professores entrevistados com maior tempo de ensino na rede pública apresentaram maior conhecimento sobre temas 
ambientais. Entretanto, a correlação entre a idade dos professores e o seu conhecimento nesses temas não foi significativa (Tabela 3). Isso demonstra que a capacitação em Educação Ambiental ocorre de forma aleatória quanto à idade, e que a avaliação de fatores que motivem ou indiquem a capacitação nessa área é complexa, visto que os professores com formação docente mais atual não revelaram possuir um melhor conhecimento que àqueles de maior tempo de obtenção de titulação acadêmica.

Gazzinelli (2002) [11] afirma que o papel do professor em sala de aula não é o de mero transmissor de conteúdo, mas de um facilitador, que cumpre sua função em fazer aflorar um conjunto de conhecimentos e experiências, que por fim, refletem na capacidade de abstração que o aluno muitas vezes já dispõe.

Entretanto, Mendes e Vaz (2009) [23] defendem que para a área da Educação Ambiental, é importante não só o conhecimento desenvolvido pelo professor, como também as formas de transmissão de temas e conceitos relativos à área, pois o trabalho escolar com a Educação Ambiental deve buscar o desenvolvimento de valores, atitudes e comportamentos humanos levando em consideração a relação entre sociedade e natureza.

Tabela 03 - Correlação entre o nível de conhecimento, a idade e o tempo de ensino público dos professores entrevistados

\begin{tabular}{lcc}
\hline \multicolumn{1}{c}{ Correlação } & Coeficiente & p-valor \\
\hline Conhecimento x Idade & 0,72 & 0,790 \\
Conhecimento x Tempo de ensino & $0,63 * *$ & $<0,01$ \\
\hline
\end{tabular}

Fonte: Autores.

** correlação significativo ao nível $p<0,01$.

Eles ainda asseveram que pela sua complexidade de abordagem, a Educação Ambiental encontra-se atrelada a habilidade dos professores em criarem maneiras para ensinar, atividade por si só complexa e sujeita a situações inesperadas. Um melhor conhecimento dos temas trabalhados facilitará a pratica docente, pois o domínio da matéria proporciona ao professor uma maior segurança e fluidez em sua aula.

Mesmo existindo políticas públicas e projetos do Governo Federal voltados para a capacitação dos professores em educação ambiental, estes acabam sendo muito pontuais e, segundo Kaplan e Loureiro (2011) [3], não devemos somente comemorar a existência de políticas públicas em Educação Ambiental no contexto escolar, devemos pensar quais os seus objetivos, justificativas, implicações e consequências políticas, sociais e educacionais para os atores sociais envolvidos.

Garrido e Meirelles (2014) [8] defendem que mesmo a Educação Ambiental sendo associada a uma educação voltada para o meio ambiente, há diferentes formas de praticá-la, dependendo de como ela é vista, pensada ou trabalhada e as diferentes maneiras de como ela vem sendo trabalhada revela diferentes percepções sobre o ambiente que nos cerca, fruto de sua construção gradual ao longo dos anos. E, segundo Grazzinelli (2002) [11, p.179]:

[...] a ação dos sujeitos está invariavelmente condicionada pelas suas representações, como se fosse possível deduzir posturas e práticas dos sujeitos a partir de um tecido de representações. [...] Não são apenas as representações que definem as práticas, mas a partir delas podem ser construídos novos modos de pensamento que desafiem os padrões de relacionamento entre o homem e o ambiente.

A Educação Ambiental depende muito da visão docente, do conjunto de percepções/ representações e da habilidade dos professores em relacioná-la com o ambiente ao seu redor, que é favorecida a partir das experiências vividas. Mas, muitas vezes, por causa do caminho árduo da profissão e a dificuldade em relacionar a temática ambiental com os conteúdos curriculares, muitos professores acabam não dando a devida importância ao tema.

Guerra et al. (2009) [24] em pesquisa sobre formação continuada em Educação Ambiental realizado em Itajaí, Santa Catarina, observaram uma série de obstáculos no processo de formação, tais como: 
[...] a falta de tempo; a instabilidade profissional; a baixa auto-estima; a fragmentação do conteúdo e atividades pontuais executadas nas escolas e impostas por técnicos e especialistas, as quais não permitem ao professor, imprimir um ritmo adequado às atividades pedagógicas [24, p.57].

A associação de todos estes fatores têm dificultado a capacitação dos professores em Educação Ambiental, o que os leva a uma fragilidade das suas práticas educacionais, não conseguindo produzir ou produzindo de forma pontual e isolada um conhecimento capaz de levar a uma reflexão/ação em seus alunos.

Para superar essa situação, o docente necessita ser dotado de estratégias didáticas e métodos de ensino que tornem o conteúdo complexo em algo compreensível e satisfatório, paralelamente a isso ele deve promover um bom desenvolvimento conceitual para tornar o aluno um praticante assíduo da Educação Ambiental. Medina (2001) [25] diz que as especificidades desse tipo de educação necessitam tanto de parâmetros temáticos quanto de métodos de capacitação exclusivos para que esta seja definitivamente introduzida nos ambientes escolares

A capacitação docente atribui-se a uma formação continuada dos mesmos e a flexibilidade e dinâmica para com o tema pelos cursos de graduação, principalmente as licenciaturas, proporcionando-lhes oportunidade de vivenciar diferentes experiências como educador, o que lhe atribuiria maior estabilidade na hora de trabalhar a Educação Ambiental [26].

Cerca de metade dos professores $(52,2 \%, \mathrm{n}=12)$, afirmaram saber conceituar o que é Educação Ambiental. Algumas dessas respostas estão relacionadas no Quadro 1. Percebeu-se que a maior parte das respostas tendeu a conceituá-la relacionando a conscientização para a preservação ambiental $(25,0 \%)$ ou a educação dos alunos para promover a harmonia entre o homem e a natureza $(16,7 \%)$. Entretanto, $47,8 \%$ não souberam responder ou responderam de forma equivocada (Tabela 04).

Quadro 01 - Respostas de alguns dos professores entrevistados agrupadas segundo seus conceitos-chave.

\begin{tabular}{|c|c|}
\hline $\begin{array}{l}\text { Conceito- } \\
\text { chave }\end{array}$ & Respostas \\
\hline $\mathrm{C} \rightarrow \mathrm{P}$ & $\begin{array}{l}\text { [Feminino] É conscientizar as pessoas sobre a preservação e conservação do } \\
\text { ambiente } \\
\text { [Masculino] Uma forma de conscientizar para que cada um possa participar } \\
\text { das melhorias do meio ambiente } \\
\text { [Masculino] É a conscientização que o indivíduo deve ter a respeito de como } \\
\text { preservar o planeta em que vivemos }\end{array}$ \\
\hline $\mathrm{C} \rightarrow \mathrm{R}$ & $\begin{array}{l}\text { [Feminino] É o meio onde se desenvolve a conscientização para os recursos } \\
\text { que melhorem o meio ambiente. Método esse que contribui para o bem do } \\
\text { planeta } \\
\text { [Feminino] É a consciência que se tem sobre os problemas que atingem o } \\
\text { meio ambiente e as formas de preservação dos mesmos }\end{array}$ \\
\hline $\mathrm{E} \rightarrow \mathrm{R}$ & $\begin{array}{l}\text { [Feminino] É o ensino de práticas educativas de como agir nos ambientes } \\
\text { nos quais são vivenciados } \\
\text { [Masculino] Maneira de passar para as pessoas a forma certa de tratar o } \\
\text { meio ambiente }\end{array}$ \\
\hline $\mathrm{E} \rightarrow \mathrm{C}$ & $\begin{array}{l}\text { [Masculino] Educar o indivíduo para uma ação consciente com o meio } \\
\text { ambiente através de práticas sustentáveis } \\
\text { [Feminino] É o ensino voltado para a abordagem de como utilizar os } \\
\text { recursos naturais com consciência }\end{array}$ \\
\hline
\end{tabular}

Fonte: Autores.

$\mathrm{C} \rightarrow \mathrm{P}$ : Conscientizar para preservar o ambiente; $\mathrm{C} \rightarrow \mathrm{R}$ Conscientizar para uso consciente dos recursos naturais; $\mathrm{E} \rightarrow \mathrm{R}$ : Educar para promover harmonia homem-natureza; $\mathrm{E} \rightarrow \mathrm{C}$ : Educar para o uso consciente dos recursos naturais. 
A evolução dos conceitos de Educação Ambiental pode estar estreitamente ligada ao conceito de meio ambiente e a maneira como este é percebido [27]. A definição inconsistente dos termos meio ambiente e Educação Ambiental, é que muitas vezes limitam o tratado desse tipo de educação, principalmente, no ensino de ciências [28].

Tabela 04 - Frequências absoluta (fa) e relativa ( $f r$, em \%) dos conceitoschaves que refletem o conceito sobre Educação Ambiental segundo os professores entrevistados $(N=16)$

\begin{tabular}{lcc}
\hline \multicolumn{1}{c}{ Conceitos-chaves } & Fa & Fr \\
\hline Conscientizar $\rightarrow$ preservar o ambiente & 5 & 31,2 \\
Conscientizar $\rightarrow$ uso consciente dos recursos naturais & 2 & 12,5 \\
Educar $\rightarrow$ Promover harmonia homem-natureza & 3 & 18,8 \\
Educar $\rightarrow$ uso consciente dos recursos naturais & 2 & 12,5 \\
Não respondido ou respostas equivocadas & 4 & 25,0 \\
\hline
\end{tabular}

Fonte: Autores.

Segundo a Política Nacional de Educação Ambiental (PNEA) o conceito de Educação Ambiental definido como:

Processos por meio dos quais o indivíduo e a coletividade constroem valores sociais, conhecimentos, habilidades, atitudes e competências voltadas para a conservação do meio ambiente, bem de uso comum do povo, essencial à sadia qualidade de vida e sua sustentabilidade [29, p.1].

Dessa forma, os professores devem perceber a Educação Ambiental como processo educativo de interações entre o homem e o meio ambiente. A maior frequência de resposta (31,2\%, Tabela 5) revela uma visão que relaciona a Educação Ambiental apenas à percepção de que a natureza é algo que se deve respeitar e preservar, mas não inclui o homem como um ser participante do meio ambiente. Esse modo de percepção pode favorecer no aluno o desenvolvimento do pensamento de que ela é intocável, visto que o docente pode repassar ações de preservação, mas, não de convivência homem-natureza harmoniosa e equilibrada.

Os professores ainda foram avaliados quanto ao saber conceituar o que é desenvolvimento sustentável. Nesse aspecto, foi verificado a capacidade dos professores em perceber o desenvolvimento sustentável como um processo que, para ser praticado adequadamente pela sociedade, deve envolver os aspectos social, ambiental e econômico.

Dentre os professores, $71,4 \%,(n=15)$ souberam defini-la. Destes, a maior parte dos professores tendeu a relacionar desenvolvimento sustentável aos aspectos socioambientais $(40,0 \%$, ou somente aos aspectos ambientais $(13,3 \%)$ e, outros $40,0 \%$ não souberam conceitualo ou não responderam (Quadro 2). 
Quadro 2 - Relação de algumas respostas segundo os aspectos social, ambiental e econômico citados no conteúdo das respostas dos professores entrevistados.

\begin{tabular}{|c|c|}
\hline $\begin{array}{c}\text { Aspectos } \\
(\%)\end{array}$ & Algumas respostas \\
\hline $\begin{array}{c}\mathrm{A} \\
(13,3)\end{array}$ & $\begin{array}{l}\text { [Masculino] É um processo que consiste em criar, obter e manter meios para } \\
\text { preservar o meio ambiente. } \\
\text { [Feminino] É algo feito para diminuir a degradação do ambiente. }\end{array}$ \\
\hline $\begin{array}{l}\text { EA } \\
(6,7)\end{array}$ & [Feminino] Crescimento econômico com proteção do meio ambiente. \\
\hline $\begin{array}{c}\text { AS } \\
(40,0)\end{array}$ & $\begin{array}{l}\text { [Feminino] São métodos e atitudes que usamos para melhor aproveitarmos os } \\
\text { recursos ambientais. } \\
\text { [Masculino] É a capacidade de produzir desenvolvimento de maneira que não } \\
\text { prejudique o meio ambiente. } \\
\text { [Feminino] Conjunto de ações voltadas para melhoria do meio ambiente. } \\
\text { [Masculino] Utilizar os recursos naturais em benefício próprio sem agrediro } \\
\text { meio ambiente. }\end{array}$ \\
\hline $\begin{array}{c}\mathrm{RE} \\
(40,0)\end{array}$ & $\begin{array}{l}\text { Aquele que atua na sociedade de modo que desenvolva o espaço social sem } \\
\text { causar prejuízos ao meio ambiente. } \\
\text { [Feminino] É o que é retirado e depois reposto. } \\
\text { [Feminino] É a forma que você usa sem destruir. } \\
\text { [Masculino] É planejar como usar os produtos de consumo, reutilizando-o } \\
\text { como benefício para o meio ambiente. }\end{array}$ \\
\hline
\end{tabular}

A: Ambiental; EA: Econômico-Ambiental; AS: Socioambiental; RE: Respostas equivocadas.

Gazzinelli (2002) [11] ressalta que o princípio em que se apoia a relação do homem com o ambiente é o de que a natureza e o ambiente têm valor apenas quando existe algum interesse utilitário envolvido. Já para Costa et al. (2012) [30], conceitua-la do ponto de vista ambiental, representando uma visão naturalista que separa o ser humano da natureza, colocando-o como mero admirador, sem laços de pertencimento e responsabilidade.

Essa visão fragmentada e, muitas vezes, naturalista reflete a falta de compreensão sobre desenvolvimento sustentável, sendo, portanto, urgente à adoção de medidas para que estes educadores recebam uma formação continuada.

A formação continuada de educadores em Educação Ambiental tem como objetivo promover uma base epistemológica e social sobre o meio ambiente, para que estes sejam mediadores no processo de construção do conhecimento, sendo, portanto, atores e autores de sua própria formação. Permitindo, dessa forma, que reflitam criticamente sobre procedimentos e métodos adotados diariamente em sala de aula, analisando e, consequentemente, aperfeiçoando a prática docente para o trabalho com as questões ambientais [24].

Matos (2009) [22] afirma que a formação inicial não deve ser vista como algo acabado, mas apenas como uma primeira etapa do processo de desenvolvimento profissional, que deverá ser constante ao longo de toda a vida.

A Educação Ambiental promove valores éticos que podem implicar em mudanças de valores com uma nova visão de mundo [31]. Assim, para que os professores consigam exercer seu papel de mediadores dos conhecimentos a respeito dos temas ambientais atuais e desenvolver uma consciência reflexiva e crítica em seus alunos sobre o ambiente que o cerca, faz-se necessário a constante construção/reconstrução dos conhecimentos na área, frente à dinâmica da Educação Ambiental. E a incompreensão ou visão limitada/equivocada, por parte dos professores, pode dificultar a sensibilização dos alunos para se tornarem atores sociais multiplicadores do saber ambiental. 


\section{CONCLUSÃO}

O nível de conhecimento dos professores entrevistados variou entre pouco ou saber em parte sobre os temas ambientais avaliados, onde o gênero masculino apresentou nível de conhecimento maior que o gênero feminino. Houve correlação significativa entre esse conhecimento e o tempo de ensino na rede pública dos professores entrevistados. Entretanto, a idade não apresentou correlação com nível de conhecimento nos diversos temas ambientais. Além disso, boa parte dos professores apresentaram dificuldades em conceituar adequadamente Educação Ambiental e desenvolvimento sustentável.

Esse cenário de informações revelam um perfil docente necessitado de capacitação em Educação Ambiental que favoreça formação aprofundada e crítica em relação às questões ambientais, sendo mais adequado que essa oportunidade de capacitar-se desde o início de sua formação superior para que construa o quanto antes o saber transdisciplinar que a Educação Ambiental exige dos educadores ambientais.

\section{REFERÊNCIAS BIBLIOGRÁFICAS}

1. Vieira FS, Matias AB, Zucon MH, Carriço JMM. Avaliação do ensino de educação ambiental a partir da percepção dos professores do município de Aracaju, Sergipe. Scientia Plena. 2009; 5(8): 1-6.

2. Santana CG, Araújo MIO. A Educação Ambiental no Ensino Médio da Escola Estadual José Amaral Lemos no Município de Pirambu-SE. Scientia Plena. 2011; 7(2): 1-8.

3. Kaplan L, Loureiro CFB. Análise crítica do discurso do programa nacional de formação de educadoras(es) ambientais - Profea: Pela não desescolarização da educação ambiental. Educação em Revista. 2011; 27(02): 177-196, doi:10.1590/S0102-46982011000200009.

4. Luca AQ, Andrade DF, Sorrentino M. O Diálogo como objeto de pesquisa na Educação Ambiental. Educação Real. 2012;37(2): 589-606.

5. Rodrigues ARS. Educação Ambiental em tempos de transição paradigmática: Entrelaçando saberes “disciplinados". Ciência \& Educação. 2014; 20(1): 195-206, doi: 10.1590/1516-731320140010012.

6. Campos RA. A educação ambiental e a formação do educador crítico: estudo de caso em uma escola da rede pública. [dissertação]. Campinas (SP): Pontifícia Universidade Católica de Campinas; 2006. $104 \mathrm{p}$.

7. Zanella L. A Questão Ambiental na Visão de Biólogos em Formação Continuada. Revista Brasileira de Educação Ambiental. 2012; 7(2): 37-43.

8. Garrido LS, Meirelles RMS. Percepção sobre meio ambiente por alunos das séries iniciais do Ensino Fundamental: considerações à luz de Marx e de Paulo Freire. Ciência \& Educação. 2014; 20(3): 671685, doi: 10.1590/1516-73132014000300010.

9. Luceno CS, Secchi MI, Jasper A, Schuck R. A implementação de práticas em Educação Ambiental em escolas municipais de Ensino Fundamental e o trabalho com adolescentes. Scientia Plena. 2013; 9(11): 1-13.

10. Bortolozzi A, Perez Filho A. Diagnóstico da educação ambiental no ensino de geografia. Cadernos de Pesquisa. 2000; 109: 145-171, doi: 10.1590/S0100-15742000000100007.

11. Gazzinelli MF. Representações do professor e implementação de currículo de educação ambiental. Cadernos de Pesquisa. 2002; 115: 173-194, doi: 10.1590/S0100-15742002000100007.

12. Freitas Filho JR, Silva LP, Freitas JJR, Freitas JCR. Educação Ambiental: Um Olhar dos Estudantes da Educação Básica Sobre o Meio Ambiente. Revista Eletrônica de Educação Ambiental em Ação. 2014; 8(49). Disponível em <http://www.revistaea.org/artigo.php?idartigo=1869\&class=25>. Acessado em 08/02/2015.

13. Cuba MA. Educação ambiental nas escolas. Revista de Educação, Cultura e Comunicação. 2010; 1(2): 23-31.

14. Reis Júnior AM. A formação do professor e a Educação Ambiental. [dissertação]. Campinas (SP): Universidade Estadual de Campinas; 2003. 194 p.

15. Jacobi PR. Educação Ambiental: o desafio da construção de um pensamento crítico, complexo e reflexivo. Educação e Pesquisa. 2005; 31(2): 233-250, doi: 10.1590/S1517-97022005000200007.

16. Andrade DF, Luca AQ, Sorrentino M. O diálogo em processos de políticas públicas de educação ambiental no Brasil. Educação \& Sociedade. 2012; 33(119): 613-630.

17. Bizerril MXA, Faria DS. Percepção de professores sobre a educação ambiental no ensino fundamental. Revista Brasileira de Estudos Pedagógicos. 2001; 82(200/201/202): 57-69. 
18. Guimarães SSM, Inforsato EC. A percepção do professor de biologia e a sua formação: A educação ambiental em questão. Ciência \& Educação. 2012; 18(3): 737-754, doi: 10.1590/S151673132012000300016.

19. Rocha JSM. Manual de Projetos Ambientais. Santa Maria: UFSM, 1997. 423 p.

20. Brasil, Ministério da Saúde, Conselho Nacional de Saúde. Comissão Nacional de Ética em Pesquisa CONEP. Resolução no 466/2012. Sobre Pesquisa Envolvendo Seres Humanos. Brasília, 2012. Disponível em: <http://conselho.saude.gov.br/resolucoes/2012/Reso466.pdf> acessado em 08/02/ 2015.

21. Mazzarino JM, Rosa DC. Práticas pedagógicas em Educação Ambiental: O necessário caminho da auto-formação. Ambiente \& educação. 2013; 18(2): 121-144.

22. Matos, MS. A formação de professores/as e de educadores/as ambientais: aproximações e distanciamentos. Pesquisa em Educação Ambiental. 2009; 4(2): 203-214.

23. Mendes R, Vaz A. Educação Ambiental no ensino formal: Narrativas de professores sobre suas experiências e perspectivas. Educação em Revista. 2009; 25(03): 395-411, doi: 10.1590/S010246982009000300019

24. Guerra AFS, Pereira YCC, Figueiredo ML, Orsi RFM. A formação continuada em Educação Ambiental no Vale do Itajaí-SC: um olhar do GEEAS-UNIVALI. Ambiente \& educação. 2009; 14(2): 51-61.

25. Medina NM. A formação dos professores em Educação Ambiental. In: Panorama da educação ambiental no ensino fundamental / Secretaria de Educação Fundamental - Brasília: MEC; SEF, 2001. $149 \mathrm{p}$.

26. Carvalho LM. A Educação Ambiental e a formação de professores. In: Panorama da educação ambiental no ensino fundamental / Secretaria de Educação Fundamental - Brasília: MEC; SEF, 2001. $149 \mathrm{p}$.

27. Fiori A. Ambiente e educação: abordagens metodológicas da percepção ambiental voltadas a uma unidade de conservação. [dissertação]. São Carlos (SP): Universidade Federal de São Carlos; 2002. $110 \mathrm{p}$.

28. Oliveira AL, Rodrigues ATO, Rodrigues MA. Educação ambiental: concepções e práticas de professores de ciências do ensino fundamental. Revista Electrónica de Enseñanza de las Ciencias. 2007; 6(3): 471-495.

29. Brasil, Congresso Nacional, Lei n 9.795 , de 27 de abril de 1999. Dispõe sobre a educação ambiental, institui a Política Nacional de Educação Ambiental e dá outras providências. Brasília: Congresso Nacional 1999.

30. Costa JR, Soares JEC, Tapia-Coral S, Mota AM. A percepção ambiental do corpo docente de uma escola pública rural em Manaus (Amazonas). Revista Brasileira de Educação Ambiental. 2012; 7: 6367.

31. Vasconcelos, HDL, Silva, E. Research in environmental education in the state of Paraíba, Brazil: analysis of its insertion and professors' commitment in post-graduate courses. Revista Brasileira de Educação Ambiental. 2015; 10: 113-125. 